\title{
Un trágico itinerario guatemalteco: determinismo y tragedia de El Norte de Gregory Nava
}

A Tragic Guatemalan Itinerary: Determinism and Tragedy in Gregory Navas's El Norte

D Leonor Taiano

University of Notre Dame

Notre Dame, Estados Unidos

Itaianoc@nd.edu

\section{RESUMEN}

El propósito de este estudio es analizar uno de los conflictos que más han marcado la realidad de los agricultores mayas de Guatemala: la migración hacia Estados Unidos. Para llevarlo a cabo, el artículo examina la película El Norte de Gregory Nava, pues esta refleja de manera subjetiva el trágico itinerario de la mayor parte de los migrantes guatemaltecos, cuyo éxodo está marcado por historias de sacrificio y de lucha. Ellos se han convertido en personajes secundarios del mundo global contemporáneo. Metodológicamente, el artículo usa un acercamiento neohistoricista que permite profundizar la manera cómo los diálogos entre los personajes principales, los desplazamientos y el contexto geopolítico del guion consienten que la película se convierta en un instrumento de reflexión sobre la complicada situación de los migrantes guatemaltecos en Estados Unidos. El estudio porta a la conclusión de que la historia de los protagonistas, Enrique y Rosa, tiene una connotación trágica porque se realiza por medio de personas que los introducen en el tenebroso mundo de la ilegalidad y, por consiguiente, se convierten en individuos invisibles de la sociedad estadounidense.

Palabras claves: El Norte; Gregory Nava; maya; migración guatemalteca; Estados Unidos 


\section{ABSTRACT}

The aim of this paper is to analyze one of the conflicts that impacted the reality of the Guatemalan Maya farmers: their migration towards the United States. To carry it out, this article examines the movie El Norte (1983) directed by Gregory Nava, which captures, in a subjective way, the tragic itinerary of several Guatemalan Migrants, whose exodus was marked by stories of sacrifice and struggle. They became secondary characters of the contemporary global world. Methodologically, the article uses a Neo-historicist approach for delving into the way in which the dialogues between the main characters, their displacements and the geopolitical context of the script allow the movie to become an instrument for debating about the complicated situation of Guatemalan migrants in the United States. This study leads to the conclusion that the protagonists' itinerary, Enrique and Rosa, has a tragic connotation because their exodus is carried out through people who introduce them to the sinister world of illegality and, as a result, they become invisible individuals of the American society.

Keywords: El Norte; Gregory Nava; maya; Guatemalan Migration; United States

\section{Introducción}

Son más de un millón y medio los guatemaltecos que han migrado hacia los Estados Unidos en busca de paz y de un mejor futuro. Casi todos ellos han puesto en riesgo su vida, pues han atravesado desiertos, mares, desagües, selvas y una serie de terrenos arriesgados y laberínticos. A modo general, la migración guatemalteca hacia Estados Unidos puede dividirse cuatro fases. La primera corresponde al periodo entre la última década del siglo XIX hasta la segunda década del siglo XX, cuando se registraron unos diecisiete mil guatemaltecos que, por razones económicas, dejaron su país para instalarse en California. La segunda etapa se sitúa desde la década de los años veinte hasta inicios de los sesenta y también se relaciona con motivos financieros. La tercera, desde los años sesenta hasta mediados de los noventa, es una consecuencia de los conflictos armados en el país centroamericano, pues tuvieron que huir de los campos minados, masacres y persecuciones de las que eran objeto. La cuarta se relaciona con los estragos económicos del período postguerra (Anguiano \& Peña, 2004, p. 47).

El contenido de este artículo se relaciona específicamente con el tercer período, por tanto, desea abordar los desafíos que los migrantes tuvieron que afrontar debido a su complicada situación legal en Estados Unidos y al riesgo de regresar a una Guatemala caracterizada por la violencia que llevó a que más de 200,000 personas fuesen asesinadas entre 1960 y 1996. En esta época tanto el ejército guatemalteco como los paramilitares perseguían a las comunidades indígenas, a los líderes sindicales, a los estudiantes y a todo aquel que, desde la perspectiva del poder, fuese portador de ideas subversivas. Entre los años 1982-1983, el gobierno guatemalteco promovió una fuerte campaña de represión que justificó el "holocausto silencioso" de aproximadamente 440 comunidades mayas (Castañeda, 2014, p. 65). 
Son precisamente el "holocausto silencioso" y la migración desesperada los motivos principales de la película El Norte (1983). Dirigida por Gregory Nava, la trama narra la historia de dos hermanos guatemaltecos, los indígenas Enrique y Rosa. Después de que su padre es asesinado por organizar una rebelión entre los recolectores de café y de que su madre es secuestrada por paramilitares, los hermanos abandonan su país para ir Estados Unidos. En Tijuana tratan con el peligroso mundo de los coyotes y, finalmente, encuentran uno que los lleva a "El Norte". En California entienden que, a pesar de poder acceder a la electricidad y al agua potable, siguen desempeñando un papel marginal y terminan confirmando que: "en nuestra tierra nos persiguen, en México no podemos estar porque es muy pobre, aquí no nos aceptan. Tal vez con la muerte encontremos la paz" (00.45.25). El final de ambos hermanos es trágico. Rosa muere de tifus y Enrique se suicida.

Este estudio analiza la naturaleza nefasta del itinerario de los personajes de Enrique y Rosa, protagonistas de El Norte (1983). El estudio del microcosmos de la película sirve como punto de inicio para analizar los factores por los que, a pesar de que el itinerario de vida de la mayor parte de los migrantes centroamericanos está marcada por historias de sacrificio y de lucha, estos se han convertido en personajes secundarios del mundo global contemporáneo. Por consiguiente, el objetivo general de esta investigación es profundizar la manera cómo los diálogos entre los personajes principales, los desplazamientos y el contenido geopolítico del guion permiten que la película se convierta en un instrumento de reflexión sobre la complicada realidad de los migrantes guatemaltecos en Estados Unidos. A partir de este objetivo general se desprenden tres objetivos específicos que son: establecer la manera cómo los problemas geopolíticos se convierten en el factor principal para la migración, profundizar sobre el papel que los coyotes desempeñan en el fracaso de la "odisea" de los migrantes, analizar los factores que impiden la realización del American Dream de los personajes.

\section{Metodología}

Es sustancial precisar que las tesis que mayormente han marcado este análisis de El Norte son las del nuevo o neo historicismo, pues estas consienten desarrollar un estudio efectivo para describir la cultura en acción y para incluir a la literatura en el complejo histórico que la crítica académica ha mantenido tradicionalmente al margen (Veeser, 2013, p. xii-xiii). Por consiguiente, este artículo adopta una visión escatológica que permite ver las estrategias discursivas institucionalizadas en el contexto de la película de Gregory Nava. El estudio ha puesto un énfasis especial en la historia económico-cultural e intelectual que marca la tragedia de los protagonistas. De hecho, este artículo se ha propuesto comprender el mensaje de El Norte, los ambientes en que se desarrolla y el contexto que agobia a los personajes principales, pues tratándose de una trama históricosocial, se ha considerado la verosimilitud del guion representado, el papel social de Enrique y Rosa y la función de los diálogos. Conjuntamente, se ha tomado en cuenta que Gregory Navas, en su condición de guionista, ha dispuesto de mayor libertad que cualquier historiador y, por lo tanto, ha podido aportar con una fuerte carga simbólica que plasma un mensaje social bastante significativo. En resumen, la metodología de esta investigación apunta sobre el desciframiento del comportamiento de los protagonistas, los mecanismos que desarrollan para afrontar la realidad y el mensaje que transmite su muerte. 


\section{Desarrollo}

La presencia de centroamericanos en Estados Unidos incrementó en las últimas décadas del siglo XX debido al caos social generado por una serie de guerras civiles que, en modo directo o indirecto, fueron del resultado de intervenciones económicas o militares extranjeras (González, 2000, p. 129). Estas llevaron a cabo una política dual y discriminatoria hacia estos nuevos inmigrantes: El servicio de inmigración y naturalización dio la bienvenida a los nicaragüenses, pero interceptó y detuvo a los guatemaltecos y salvadoreños (González, 2000, p. 129).

Adicionalmente, Estados Unidos optó por negarles el estatuto de refugiados, condenado a quienes lograban atravesar las fronteras a trabajar ilegalmente (González, 2002, p. 130). A pesar de que varias organizaciones humanitarias denunciaron que el gobierno estadounidense patrocinó, en cierto modo, el terror en la región, las administraciones de Reagan y Bush, obsesionadas con la erradicación del comunismo en la región, rechazaron asistir los millones de personas que, desde la frontera mexicano-estadounidense, pedían a gritos ser recibidas para escapar del terror (González, 2002, p. 131).

\subsection{La United Fruit Company en Guatemala}

A lo largo del siglo XX, los presidentes guatemaltecos protegieron los intereses de una compañía en particular: la United Fruit Company. El presidente Jorge Ubico, quien gobernó desde 1931 hasta 1944, sobrepasó a sus predecesores en los favores concedidos a esta entidad. Cuando Ubico dejó el poder, United Fruit Company ganó más de un millón de acres de banana en los campos centroamericanas y tenía bajo su poder el sistema ferroviario (Bucheli, 2003, p. 82). Ubico era un simpatizante del fascismo en un país en la que los cafetales guatemaltecos pertenecían a una elite de origen alemán (González, 2000, p. 134). Sin embargo, con la ayuda de Washington, en 1942 confiscó gran parte de las plantaciones de café, facilitando la introducción de capitales estadounidenses. Estas medidas trajeron consigo una considerable prosperidad mientras la guerra duró, lo que le permitió financiar un trabajo público ambicioso y el mejor sistema de carreteras de América Central. El progreso, sin embargo, vino a un precio muy alto. Ubico forzó a la nulateniente población maya para que trabajara en los proyectos gubernamentales en vez de pagar impuestos. Hizo que los indígenas llevasen cartillas y utilizó leyes contra el vagabundeo para obligarlos a trabajar para los grandes terratenientes (Gleijeses, 1989, p. 26). Efectivamente, Guatemala se convirtió en un estado guarnición estadounidense por más de cuarenta años. Tras el golpe de estado de Carlos de Castillo Armas y el derrocamiento del presidente Jacobo Árbenz Guzmán, el 3 de julio de 1954 se inicia en Guatemala el periodo conocido como la Contrarrevolución, que duró por aproximadamente tres décadas (Bucheli, 2003, p. 84).

En el gobierno de Castillo Armas se creó el Comité Nacional de Defensa contra el Comunismo, permitiendo que las autoridades pudiesen ordenar la detención de cualquier persona sospechosa de ideas izquierdistas y dio lugar a una serie de arrestos abusivos, secuestros, torturas, exilios forzados y migración indocumentada (Rostica, 2007, p. 75). Conjuntamente, los hechos políticos y militares sucedidos en Guatemala fueron un ejemplo claro del incumplimiento de la constitución y del abuso de poder. Después del asesinato de Castillo de Armas en 1957, el ejército mantuvo el control del poder, casi de forma absoluta, hasta 1986, ya sea por la vía de elecciones fraudulentas 
o por medio de golpes de estado. La presencia de los militares en el poder se justificaba por la ya mencionada lucha contra el comunismo, el cual era contrario a los intereses de Estados Unidos en Centroamérica. Si bien entre los años 1966 a 1970 el presidente de Guatemala fue un civil, el licenciado Julio César Méndez Montenegro, quienes gobernaron realmente fueron los militares (Rostica, 2007, p. 75).

De hecho, al momento de entregarle el mando se le impuso un "pacto de condiciones" que anulaba su poder de decisión como presidente y en especial sus facultades constitucionales como comandante en jefe del ejército. Posteriormente, entre 1954 y 1986 se subsiguieron democracias fantoches y regímenes militares. Entre los que se encuentra los gobiernos de Fernando Romeo Lucas García (1978-1982), de José Efraín Ríos Montt y de Oscar Humberto Mejía Víctores (Rostica, 2007, p. 82). La gestión del primero inició cuyo mandato se caracterizó por una fuerte represión política, una constante violación de los derechos humanos, fuertes acciones contra la guerrilla y el genocidio maya. Consecutivamente, Ríos Montt tomó el poder mediante un golpe de estado realizado por la junta militar que derrotó a Lucas García. Durante esta gestión se crearon los “Tribunales de Fuero Especial" que eran juzgados anónimos que ordenaban el fusilamiento de personas encarceladas (Nikken, 2003, p. 162). Su gobierno se caracterizó por la política de la tierra arrasada, que destruía comunidades enteras. En su mandato el ejército y las Patrullas de Autodefensa Civil fueron protagonistas de asesinatos y violaciones a los derechos humanos (Nikken, 2003, p. 163).

\subsection{Guatemala en la historia de los Xuncax}

La película está dividida en tres partes. La primera, titulada Arturo Xuncax, está ambientada en el pueblo de San Pedro. Esta parte muestra la paz en la que vivían los mayas hasta la guerra civil que condujo a la muerte de gran parte de sus habitantes y al éxodo masivo. La segunda parte se titula "El coyote". En esta sección se muestra el itinerario de viaje de los hermanos, sus problemas con los coyotes y su paso por la frontera. La tercera parte, titulada "El Norte", muestra las dificultades de los hermanos como migrantes ilegales y termina con la muerte de ambos.

El contexto histórico-político guatemalteco es relevante en la primera parte de El Norte. La película muestra los estragos de la guerra civil en la Guatemala rural. En los primeros treinta minutos, las escenas evocan la constante opresión que los campesinos de Ixil han sufrido en manos de los terratenientes. Las imágenes exhiben los traumatismos de una sociedad vencida por las injusticias étnico-sociales. Estos han conducido al desastre material y familiar de los mayas, representados por el microcosmos de la familia Xuncax. Arturo, padre de los dos protagonistas, es un indígena orgulloso que trabaja recolectando café. Este organiza a un grupo de peones para que se revelen contra los desafueros de los terratenientes y del ejército.

Para demostrar la precaria condición de los indígenas y aumentar el pathos en la película, El Norte presenta una serie de escenas con primerísimos planos de campesinos con las manos callosas, con expresiones de cansancio, los pies descalzos y los rostros sudorosos. Estos aluden a una sociedad jerárquica basada en la explotación del indígena. Los cuerpos se convierten en un elemento clave para mostrar el abismo social que los separa de los militares y, principalmente, de los latifundistas. Por consiguiente, las menciones al omnipresente, aunque invisible, terrateniente extranjero, demuestran que los campesinos mayas desean combatir o, al menos, manifestar cierta 
resistencia. El personaje de Arturo rechaza ser sometido a un yugo extranjero que priva a los locales del derecho a la propiedad. Consciente de su falta de derechos, Arturo busca protección en el derecho ancestral que lo hace propietario de aquella tierra.

Arturo resume en sí el espíritu de rebelión que caracterizó a los pueblos indígenas y al campesinado guatemalteco de finales de los años 70 e inicios de los 80 . Su lucha alude a la resistencia del pueblo frente a los invasores desde hace más de quinientos años, pero es importante resaltar que su rebelión alude a los levantamientos maya de los 80, estos constituyeron un proceso de lucha popular en el que los mayas hicieron una serie de esfuerzos para tomar las riendas del propio destino, demostrando que deseaban poner fin a la explotación agrícola o minera y a la manipulación política que ponía en riesgo sus lugares sagrados y su ecosistema. Se trata de un rechazo radical a siglos de opresión basada en parámetros étnico-sociales. En este periodo, los agricultores mayas pusieron en cuestión las estructuras de poder que generaban el racismo y el empobrecimiento de los indígenas en general y se propusieron cambiar el sistema capitalista de raíz para construir otro sistema más humano que responda a sus necesidades (Castellanos, 2004, p. 25).

Este contexto se percibe, por ejemplo, en uno de los diálogos más significativos de la película, aquel entre Arturo y Enrique, en él se alude al abuso de poder, a la opresión, a la explotación inescrupulosa de los mayas y de sus tierras, al miedo que sienten los indígenas y a la necesidad de luchar por reivindicar sus derechos y recuperar la propia tierra, puesta en peligro por la codicia de otros:

Arturo: Ya no aguantamos el abuso

Enrique: Tengo miedo, pues...

Arturo: También yo, pero algunas veces alguien tiene que luchar por nuestra tierra. No hay más remedio [...] El rico llegó al pueblo, no es del pueblo. Llegaron buscando el buen tierra. Nadie busca el mal tierra. El mal tierra no trae pleito, por eso se asentaron con nosotros. Porque este es buen tierra...Voy a decirte algo, Enrique. Algo que el vida me enseñó. Yo conocí el fincas de México que le dicen. Fincas del costa, trabajé en mucho lugar y en todo lugar, siempre la misma cosa, para el rico el campesino solamente brazo. Eso creen que somos, puro brazo. Sus animales son tratados mejor que nosotros. Muchos años andamos buscando y probando que el rico entienda que el pobre tiene corazón y alma, que siente. Somos gente...Todos iguales (00:09:40).

Es importante señalar que Gregory Nava insiste mucho en la imprecisión gramatical que los indígenas hacen del español, principalmente cuando los personajes aluden al extranjero que vino a ocupar sus tierras. Podría pensarse que, por medio de las imprecisiones sintácticas, el guionista quiere indicar que el presente de colonialismo informal guatemalteco es un continuum de su pasado colonial. Más allá de este detalle, conviene enfatizar que Arturo Xuncax se convierte así en lo que Eric J. Hobsbawm define como un rebelde primitivo (Hobsbawm, 1974, p. 11-12). Es decir, una persona que no nació en un mundo capitalista o, para ser más precisos, forma parte de este en modo periférico. Es su posición marginalizada la que hace que adquiera conciencia política de primera mano, tomando en cuenta que forma parte de una gran masa unida por vínculos de solidaridad tribal y territorial. Sin embargo, es víctima de delación y termina siendo denunciado al ejército que lo asesina y posteriormente cuelga su cabeza en un árbol. Ese es el 
pago que el indígena recibe por enfrentarse cara a cara contra los militares. De manera épica, Arturo desobedece al yugo de su destino y termina convirtiéndose en un héroe caído. Aunque está dotado de fuerza y valor, virtudes de gran importancia en el universo homérico, en la sociedad post-heroica contemporánea no puede desempeñar un lugar protagónico. A pesar de que sucumbe combatiendo por sus ideales y por su tierra, su muerte no es gloriosa, no es una kalòs thánatos, pues el determinismo étnico social lo ha predestinado para el anonimato (Vernan, 1978, p. 56).

De igual manera, el secuestro, esta vez en manos de los paramilitares, de la esposa de Arturo, Lupe Xuncax, refleja los abusos a los que son sometidos los "sin derechos" dentro de la sociedad guatemalteca. El Norte recupera aquello que las versiones oficiales de la historia guatemalteca desean olvidar: el poder en Guatemala tuvo como máximo aliado la violencia. Por medio de la represión, la tortura y la impunidad se construyó un sistema desigualitario que aniquiló cualquier forma de heroísmo y de resistencia. De hecho, a través de los diálogos entre los personajes, El Norte puede ser considerado como el primer exponente de un proyecto cinematográfico que incluye las películas El Norte (1983) propiamente dicho, My Family (1995) y Bordertown (2007) y que está dedicado a retratar el delicado contexto latinoamericano y su relación con la migración hispánica hacia los Estados Unidos. La película critica firmemente la sociedad contemporánea por donde se desplazan los personajes (trátese de Guatemala, México o Estados Unidos). A pesar del epos que marca sus historias, todos ellos pueden ser definidos como antihéroes del mundo global. Sus epopeyas son destinadas a caer en el olvido en medio del caos de la guerra y de la discriminación.

En su análisis de El Norte, Jean Christine List considera que el gran pathos que marca la película tiene toques melodramáticos provenientes de la tradición de las telenovelas latinoamericanas (List, 1992, p. 19). Este melodrama estaría construido en base a la idea de Estados Unidos como una suerte de tierra prometida, pero termina fusionando los problemas sociopolíticos de los indígenas de Guatemala con el pragmatismo estadounidense. List piensa que la película hace un uso excesivo de los villanos estereotipados, principalmente en los personajes que representan a los oficiales de migración (List, 1992, p. 51). Esta manipulación de los estereotipos encerraría un mensaje propagandístico social especifico:

\footnotetext{
El Norte shift to a different social message: we should accept all Latino immigrants because they are warm and loving people and good hard workers. Their countries are too corrupt for them to live in and, besides, they will suffer any danger or humiliation to get across the border to live in the United States. The threat of deportation is the film's villain. The final implication is that hard-working men like Enrique could indeed succeed within this economic system in a few bad employers could not hold the threat of deportation over their heads" (List, 1989, p. 27).
}

Es evidente que, en su deseo de establecer cierta filiación entre la película con las telenovelas latinoamericanas, List realiza un análisis desde una perspectiva aparentemente racionalista que, debido a un cierto desconocimiento del contexto histórico, le induce a ver solamente los elementos propagandísticos pro-migrantes. Por consiguiente, el crítico evita analizar la película desde los aspectos que le permitirían reconocer un sentido mucho más profundo de la trama. List no logra poner en relieve la cuestión de los sujetos, individuales y colectivos, que se deshacen y 
se rehacen a lo largo de la película. El estudioso olvida que si bien en el texto hay la sociabilidad primordial que caracteriza los melodramas latinoamericanos (por medio de la solidaridad entre parientes, vecinos, amigos), El Norte es principalmente una muestra de la manera cómo esta armonía es destruida por los crímenes de lesa humanidad que ocurren en Centro América y por las transformaciones operadas por el utilitarismo en Estados Unidos.

Efectivamente, un punto importante de El Norte radica en el hecho de que la primera parte demuestra que los conflictos de Guatemala invaden el locus amoenus de la aldea maya y destruyen a la comunidad de San Pedro, generando muertes, desapariciones y diásporas. Antes de que "el rico llegue al pueblo", los mayas vivían bajo los códigos milenarios de solidaridad indígena. Estos se desmoronan delante de los ojos del espectador, demostrando que el paraíso se convierte rápidamente en un infierno, en una guerra fratricida. De hecho, por medio de primeros planos, las cámaras muestran que tanto los rebeldes como los soldados son indígenas. La destrucción de San Pedro sucede por medio de un fratricidio maya, una guerra entre indígenas rebeldes e indígenas que apoyan al poder. El rico, como diría Arturo, no apunta el gatillo. El enfrentamiento es vivido entre las clases sociales ínfimas, entre aquellos que eligen la rebelión y quienes aceptan la sumisión.

En otras palabras, por medio de la pugna entre indígenas soldados e indígenas rebeldes, la película afronta un tema central de la sociedad guatemalteca: la diferentes relaciones que los dominados tienen hacia los dominadores. El enfrentamiento entre los soldados, los paramilitares y los campesinos revela la manera cómo la sociedad guatemalteca está marcada por una lucha entre Arieles y Calibanes. Entre militares y paramilitares que protegen los derechos de un Próspero poderoso e invisible contra campesinos que reclaman las riquezas de la tierra en la que nacieron. La película manifiesta que este fratricidio es estéril, pues las muertes no dan lugar a la fundación de una ciudad o un imperio, como ocurre en los casos de Caín y Abel o el de Rómulo y Remo, sino que conduce a la perdición total. Los militares no conseguirán grandes ventajas con su fidelidad al poder y los campesinos no lograrán reconquistar su tierra. Lo único que ambas partes obtendrán es los estragos de una violencia que confirma el determinismo de los estamentos sociales y que los hace vivir en un eterno estado de terror y los conduce a huir constantemente.

Rosa: La Armada va a regresar. Tengo miedo. La gente se está yendo del pueblo.

Enrique: Yo también me voy. Tengo que irme. Mientras yo esté aquí la vida de ustedes está en peligro.

Rosa: ¿Pero dónde?

Enrique: Al Norte... (oo:23:25)

En efecto, después de que los militares matan a Arturo y los paramilitares secuestran a Lupe, el miedo se convierte en un motivo dominante a lo largo de la trama. Los protagonistas se sienten en peligro en el propio territorio y juzgan necesario escapar hacia "El Norte". Es indudable que por medio de la decisión de dejar el país, Enrique y Rosa desean escapar a la muerte, pero no lograrán hacerlo. A partir de aquel momento, la historia de los hermanos toma una connotación pseudo-épica. Aunque van a comenzar un éxodo marcado por duras pruebas, van a recorrer desiertos, resistir agresiones, combatir contra los “monstruos" de los abusos laborales y de las leyes inhumanas, su viaje simplemente servirá para confirmar su condición de subordinados y para 
hacerles encontrar la muerte de la que trataron de escapar. Sus dificultades no son pruebas que les permiten confirmar su propia dignidad, inteligencia o capacidad para superar los obstáculos, son simplemente evidencias de un determinismo mundial que los convierte en los desafortunados Ulises post-heroicos. Aunque su fuga y la larga travesía desde Guatemala hasta Estados Unidos podría relacionarse con las míticas historias de Eneas, Ulises o Moisés, su destino es muy diferente, pues como bien reconoce Rosa durante su agonía, en Estados Unidos no los aceptan.

\subsection{El coyote}

En relación con lo anterior, Arthur Brakel considera que, si bien El Norte corresponde al esquema general de la épica migratoria, la estructura de la película y el tema principal derivan de una forma épica más extensiva, en la que el viaje toma una connotación más espiritual que geográfica. El estudioso piensa que la película distorsiona un poco la tradición del viaje del infierno al paraíso, presente por ejemplo en la Divina Comedia, haciendo que los protagonistas abandonen un lugar que antes de la guerra civil tenía connotaciones paradisiacas para verse sometidos en un mundo ajeno e infernal (Brakel, 2004, p. 166). Según Brakel, un papel importante en esta distorsión del viaje dantesco lo desempeñan los diferentes “Virgilios" que aparecen en la película. Estos son don Ramón, quien le preanuncia que la frontera mexicano-estadounidense es peor que la guerra; un mexicano que les da un aventón; el pasajero del autobús que les dice que Tijuana es "el cagadero del mundo"; el coyote Jaime y el coyote Raimundo, quien los hace llegar a Estados Unidos por medio del drenaje que conecta Tijuana con San Diego y los hace encontrar a don Mocte, un chicano explotador de ilegales (Brakel, 2004, p. 168).

Aunque considero que la tesis de Brakel es interesante, pienso que el desplazamiento de los protagonistas sí sigue el esquema de la épica migratoria, pero demuestra la imposibilidad de que Enrique y Rosa se conviertan en héroes debido a que se encuentran en una sociedad postheroica que no ve en el viaje una vía de crecimiento personal. Por consiguiente, considero que las personas que guiaron a los dos hermanos en su viaje, principalmente los coyotes, constituyen una deformación de los guías arquetípicos de los éxodos que han marcado la literatura universal. En otras palabras, considero que Jaime y Raimundo constituyen una deformación del arquetipo de Moisés, legislador y libertador de los hebreos, o de Eneas, fundador de un imperio. Don Raimundo no conducirá a los hermanos guatemaltecos a la liberación, los llevará hacia la clandestinidad, la explotación laboral y la muerte.

Don Raimundo: ¿Tu hermana es fuerte?

Enrique: A mí se me hace que mi hermana es más fuerte que usted y yo juntos.

Don Raimundo: iQué bien! Porque yo no los voy a cruzar por las montañas. Ya se ha vuelto muy peligroso ese paso. Nos queda otro, el drenaje y es horrible. El antiguo drenaje que conecta Tijuana y Estados Unidos. Hace mucho tiempo que no se usa, por eso los túneles están vacíos. Los más seguros son los más chicos, pero van a tener que ir gateando por varios kilómetros. Es más seguro que las montañas, pero les advierto que está de la chingada. No van a poder oír nada. No van a poder ver y el olor... Es más seguro, pero la mayoría prefiere ir por las montañas, aunque los roben o balaceen (00:55:24) 
Es muy significativo el hecho de que don Raimundo haga que los hermanos ingresen a Estados Unidos por medio del drenaje, pues este representa abiertamente una entrada a través del mundo subterráneo. La escena de los hermanos gateando por la insalubre red de saneamiento se combina con un encuadramiento del U. S. Border Patrol MD Helicopters $600 \mathrm{~N}$ que sobrevuela la frontera estadounidense-mexicana, sugiriendo el encuentro/desencuentro del mundo de la legalidad con el de la clandestinidad. El drenaje es un microcosmos que tiene sus propias leyes, sus propias creaturas. Efectivamente, Enrique y Rosa serán agredidos por un grupo de ratas que se sentirán amenazadas por la presencia de los guatemaltecos. Hay una gran dramaticidad en esta escena y en el posterior encuentro de los hermanos con su coyote, bajo las luces artificiales de San Diego. El desplazamiento por el mundo subterráneo no los conduce de la oscuridad a la verdadera luz, sino que los guía hacia un universo donde reina lo artificial. No existe un verdadero contraste entre el territorio fundacional de Guatemala y el territorio conceptual de El Norte. La película muestra que, bajo la apariencia afable de un mundo de oportunidades, Estados Unidos es una sociedad que no permite la movilidad social.

La manera cómo los hermanos ingresan en "El Norte" anticipa que estos van a formar parte de los invisibles. Su mundo es el mundo subterráneo, una suerte de topografía de la exclusión. Los protagonistas no lograrán tomar las riendas de su vida, no podrán reapropiarse de sus existencias, no habrá conquista de seguridad económica y estabilidad laboral, tampoco habrá un nostos o viaje de retorno. Enrique y Rosa no son como Ulises que regresa a casa después de diez años de tribulaciones. La fase bélica guatemalteca es solamente el inicio de una serie de sufrimientos, una preparación para infortunios mayores.

Es evidente que Gregory Nava desea poner énfasis en la vulnerabilidad que el viaje con traficantes envuelve. Con la agresión de las ratas, que a largo plazo causarán la muerte de Rosa con tifus, alude a los riesgos a los que el viajero ilegal se somete. En este sentido, se puede decir que El Norte es una de las primeras obras cinematográficas que demuestra un deseo de revelar las condiciones infrahumanas que los coyotes imponen a sus clientes.

Este tipo de espíritu de denuncia se puede percibir también en la obra de Luis Alberto Urrea titulada The Devil's Highway. En esta obra, que consiste en una importante recolección de testimonios e investigaciones sobre el paso de México a Estados Unidos, Urrea define a los coyotes como verdaderos gánsteres, protegidos incluso por autoridades gubernamentales y por la policía de ambos lados de la frontera. A veces llamados coyotes, otras veces polleros, los traficantes de seres humanos son peligrosos criminales de una red cada vez mejor organizada:

In the new organized crime hierarchies of human smuggling, the actual Coyotes are middle-management thugs. The old Coyote, the scruffy punk leading a ragtag group of Guatemalans into San Diego via the bogs and industrial parks of Chula Vista is becoming extinct (Urrea, 1998, p. 60)

A pesar de que Jaime y Raimundo, los coyotes de El Norte, forman parte de esa generación en extinción que menciona Urrea, analizar su función en la película es importante, pues al igual que sus sofisticados sucesores, estos contribuyen a que la economía estadounidense obtenga grandes ventajas de la mano de obra ilegal, pues esta es más flexible y menos onerosa. La película, al igual que el texto de Urrea, también sugiere que la fragilidad jurídica de los migrantes y las políticas migratorias cada vez más restrictivas sirven como caldo de cultivo para la proliferación de los traficantes de migrantes. 
A pesar de la diferencia temporal entre la producción de los textos (El Norte fue filmado en 1983 y The Devil's Highway: A True Story fue publicada en 1998). Ambas obras ponen en evidencia que el cruce de la frontera mexicano-estadounidense no está marcado por la caída de la maná del cielo. En el caso de El Norte, Enrique y Rosa atraviesan la frontera entre ratas y cloacas, no en una tierra de leche y miel. Aunque Rosa puso ofrendas a la virgen antes de dejar su pueblo, en su éxodo no hay señales que indiquen que los mayas son un pueblo escogido. Su viaje no los conduce hacia el triunfo o la liberación, sino que los Ileva hacia la inestabilidad característica del estatuto de migrante ilegal y a la muerte.

El intento de robo de Jaime y las condiciones precarias a las que Raimundo somete a los dos hermanos guatemaltecos sirven para demostrar que, oponiéndose al comportamiento del liberador de los hebreos y al héroe de los troyanos, el coyote no es solidario con la gente de su pueblo que sufre de pobreza y opresión. De hecho, este busca solamente de lucrarse a través de su viaje, representando una versión degenerada de la figura del libertador de un pueblo. Ni Jaime ni Raimundo encarnan un instrumento divino que trae la salvación de los errantes hermanos guatemaltecos, son simplemente una pieza que forma parte de un grande corpus de corrupción, del que forman parte los gobernantes de Guatemala, los soldados, las multinacionales, los coyotes, los explotadores de inmigrantes, entre otros. En otras palabras, los coyotes de El Norte forman parte de una cadena de individuos que pueden abusar de los desheredados de la globalización.

\subsection{El Norte}

En su objetivo de hacer de la película una representación de las brutales peripecias sufridas por los latinoamericanos que deben huir de sus países debido al caos geopolítico que en parte ha sido generado por Estados Unidos, El Norte se presenta como una suerte de conmemoración al sufrimiento vivido por quienes atraviesan la frontera que supuestamente divide al continente americano entre el rico norte y los países latinoamericanos. La historia de Enrique y Rosa revive los problemas y traumas de quienes deben abandonar su tierra natal para proteger su vida. En otras palabras, la película trata de luchar contra el silencio que marca la tragedia de la migración ilegal de quienes, a pesar de que se han visto forzados a la migración, no logran obtener un estatuto de refugiados.

En consecuencia, El Norte tiene una connotación trágica, pues su objetivo es mostrar las vicisitudes que viven los migrantes y las consecuencias psicológicas y físicas que esta migración conlleva. En otras palabras, la película se convierte en un vehículo de comunicación entre aquellos latinoamericanos que han experimentado la diáspora y se encuentran frente a la hostilidad de un país extranjero. Efectivamente, aunque en algunos momentos parece que es posible encontrar en Estados Unidos una nueva patria, los episodios en que están a punto de ser descubiertos por la migración, la falta de seguridad laboral y de asistencia médica exteriorizan la imposibilidad de que "El Norte" se convierta en un nuevo hogar. Enrique y Rosa son prisioneros de su condición migratoria. Los intentos para escapar del peligro de su país natal les han conducido a riesgos mayores. De hecho, Rosa termina muriendo de tifus, adquirido por los mordiscos de las ratas que la agredieron en el drenaje y Enrique termina auto-sacrificándose por medio de un suicidio que, al igual que el sacrificio de su padre, no tiene ninguna trascendencia, pues representa la eliminación de un individuo que "no existe", representa el auto-aniquilamiento de un "sin documentos". El Norte transmite un mensaje muy claro: el migrante sin documentos es un eterno fugitivo, destinado a vivir de pequeños trabajos y a cambiar constantemente de lugar. 
Enrique: Después de todo encontramos la salida. Digamos salud por esa escapada [de los policías de migración]. Ya encontraremos otro...

Jorge: iSi no es tan fácil, mano! Andar sin trabajo aquí está de la fregada. Se ha venido mucha gente de allá. Ya no hay tanto trabajo como antes. ¿̇abes que el pocho [chicano] quien nos denunció? [...] Desde que te promovieron te tiene odio... (01:52:00)

Este diálogo entre Enrique y su colega del restaurante es revelador. En primer lugar, pone en evidencia la vida de persecución de los inmigrantes indocumentados, quienes siempre deben huir de los controles migratorios. En segundo lugar, señala las dificultades de estos para encontrar trabajo. En tercer lugar, sugiere que el estigma de la "latinidad" también incumbe a los ciudadanos estadounidense de origen hispanoamericano. Estos son la prueba de la poca movilidad social que existe en Estados Unidos, pues en la película desempeñan papeles tan viles como el del coyote. De hecho, son quienes se dedican a ser explotadores de ilegales o a delatarlos cuando sienten que estos pueden "robarle" su trabajo precario, pues, aunque son ciudadanos estadounidenses jus soli, estos personajes viven una existencia entre dos mundos. Ese estado intermedio los convierte en ciudadanos de segunda zona, integrantes de lo que la mayoría estadounidense considera una subcultura.

Finalmente, mientras Rosa agoniza debido al tifus, los dos hermanos tienen una conversación de gran importancia dentro de la película. Rosa y Enrique hablan de la vida como un drama terreno estrechamente relacionado con la desesperación. La vida es dolor, es la imposibilidad de encontrar la felicidad y la paz. Antes de morir, Rosa concluye que la muerte no es una condena, es una liberación.

Rosa: La vida aquí es muy difícil. iNo somos libres! ¿Verdad que no somos libres?

Enrique: Sí, es difícil la vida aquí [...]

Rosa: ¿Cuándo vamos a encontrar un lugar? Tal vez solo muertos encontraremos un lugarcito (02:03:50).

La muerte es la última probabilidad para encontrar un lugar, esas son las palabras de Rosa antes de fallecer. Este mensaje llega claramente a los oídos de Enrique, quien terminará suicidándose. El suicidio se convierte así en un acto para escapar de las tribulaciones. Es también el símbolo de la perdida de ilusiones. Al final de la película, los dos protagonistas ya están cansados de la existencia. La muerte de ambos, principalmente la de Enrique, es presentada como la consecuencia de un razonamiento lógico, no como una desgracia o un error. Es la liberación de un mundo que no los merece.

\section{Conclusiones}

Como indiqué en las primeras páginas, este estudio partió del deseo de analizar los aspectos que hacen de la epopeya de Enrique y Rosa, protagonistas de El Norte, una experiencia nefasta. Después de haber examinado las tres partes que constituyen la película: "Arturo Xuncax", "El coyote” y "El Norte", se puede concluir que la historia de los dos hermanos tiene una connotación trágica debido a diversos aspectos. El primero radica en el hecho del fratricidio estéril que conlleva una guerra civil que consume la tranquilidad de Guatemala. El segundo se relaciona con la naturaleza 
de quienes guían a los dos hermanos en su éxodo, pues los coyotes son seres que introducen a los protagonistas en el tenebroso mundo de la ilegalidad. El tercero, finalmente, lo constituye la migración ilegal propiamente dicha. Enrique y Rosa no pueden usufructuar de los beneficios de la sociedad estadounidense porque forman parte de aquellos individuos invisibles, que simplemente sirven como mano de obra barata que puede ser fácilmente reemplazada.

La representación que la película hace de los dos hermanos guatemaltecos permite explorar la vulnerabilidad social de quienes, a pesar de que huyen de tragedias geopolíticas indirectamente producidas por Estados Unidos, no logran obtener una visa de refugiados en "El Norte" y deben conformarse con formar parte de la masa ilegal. De hecho, los constantes reenvíos que en la primera parte se hacen al contexto político-social guatemalteco consienten que el espectador pueda asociar la migración de los protagonistas con los efectos de un colonialismo informal que tiende a fortaleces las categorías estamentales impuestas por la globalización.

El éxodo, la vida en una tierra extranjera y la muerte de los protagonistas manifiestan que la epopeya de Rosa y Enrique es nefasta porque el hispano se ha convertido en el antihéroe de la era post-heroica. Sus tribulaciones afirman su papel de subordinados. El mensaje de El Norte es pesimista. Los migrantes ilegales tienen un destino infausto que les impide vivir con dignidad y tener una bella muerte o kalos thánatos.

A lo largo de esta investigación —al igual que todas las que tratan sobre el "holocausto silencioso" - han surgido una serie de limitaciones debido a que el verdadero número de personas que fueron sacrificadas en Guatemala no son lo suficientemente precisas. Es por ello que el estudio se basó principalmente en la subjetividad del guion cinematográfico para reconstruir la tragedia colectiva maya y se orientó, principalmente, a analizar las cuestiones relacionadas con los Estados Unidos. En cualquier caso, los resultados que se presentaron en este artículo ofrecieron una perspectiva para explorar la relación directamente proporcional entre la migración y la confirmación del determinismo étnico social. Sin embargo, se reconoce que en el futuro sería significativo estudiar más detenidamente la vida de los protagonistas en lo que atañe a su lugar de origen, al estilo de vida, a los peligros de las agresiones militares y paramilitares que los portaron a sentirse en riesgo y optar por huir hacia “El Norte".

\section{REFERENCIAS}

Anguiano, M. E., \& Peña, A. T. (2007). Políticas de seguridad fronteriza y nuevas rutas de movilidad de migrantes mexicanos y guatemaltecos. Liminar. Estudios sociales y humanísticos, (2), 47-65. https://doi. org/10.29043/liminar.v5i2.250

Brakel, A. (2004). "El Norte”, Deracination and Circularity: An Epic Gone Awry. Bilingual Review/La Revista Bilingüe, 28(2), 166-175. https://www.jstor.org/stable/25745857

Bucheli, M. (2003). United Fruit Company in Latin America. En, Striffler, S. y M. Moberg (Coord.), Banana Wars (pp. 80-100). Duke University Press.

Cambranes, J. C. (2004). Ruch'ojinem qalewal: 500 años de lucha por la tierra: estudios sobre propiedad rural y reforma agraria en Guatemala. Cholsamaj Fundación. 
Castañeda, M. E. V. (2014). Los pelotones de la muerte.: La construcción de los perpetradores del genocidio guatemalteco. El Colegio de México AC.

Gleijeses, P. (1989). La aldea de Ubico: Guatemala, 1931-1944. Mesoamérica, 10 (17), 25-6o. https://dialnet. unirioja.es/servlet/articulo?codigo $=3734621$

González, J. (2000). Harvest of empire: A history of Latinos in America. Penguin Group USA.

Groody, D. G. (2009). Jesus and the undocumented immigrant: A spiritual geography of a crucified people. Theologicalstudies,70(2),298-316.https://journals.sagepub.com/doi/abs/10.1177/004056390907000204

Hobsbawm, E. J. (1974). Rebeldes primitivos: estudos sobre formas arcaicas de movimentos sociais nos séculos XIX eXX. Zahar Editores.

List, J. C. (1989). El Norte, Ideology and immigration. Jump Cut: A Review of Contemporary Media, 34, 27-31.

List, J. C. (1992). Chicano images: Strategies for ethnic self-representation in mainstream cinema (Tesis doctoral). Northwestern University. Evanston.

Nava, G., (1983). El Norte. Cinecom International.

Nikken, P. (2003). La función consultiva de la Corte Interamericana de Derechos Humanos. Memoria del Seminario: El Sistema Interamericano de Protección de los Derechos Humanos, 1, 161-184. https://archivos. juridicas.unam.mx/www/bjv/libros/5/2454/10.pdf

Nouss, A., \& Laplantine, F. (1997). Le métissage: un exposé pour comprendre, un essai pour réfléchir. Flammarion.

Rostica, J. (2007). Las organizaciones mayas de Guatemala y el diálogo intercultural. Política y culturas: septiembre, 27, 75-97. https://polcul.xoc.uam.mx/index.php/polcul/article/view/1021

Schirmer, J. G. (1999). Intimidades del proyecto político de los militares en Guatemala. FLACSO.

Urrea, L. A. (1998). The devil's highway: A true story. Back Bay Books.

Veeser, H. (Ed.). (2013). The new historicism. Routledge.

Vernant, J. P. (1978). A bela morte e o cadáver ultrajado. Discurso, 9, 31-62. https://doi.org/10.11606/issn.23188863.discurso.1978.37846

\section{AUTORA}

Leonor Taiano. Doctora en Humanidades y Ciencias Sociales (Universitetet i Troms $\varnothing$-Noruega). Actualmente está concluyendo un segundo doctorado en estudios hispánicos (University of Notre Dame-Estados Unidos). Sus publicaciones se centran en la relación entre literatura y propaganda, las cuestiones de la identidad y las narrativas de la migración.

\section{Conflicto de intereses}

La autora declara que no existió conflicto de interés posible.

\section{Financiamiento}

No existió asistencia financiera de partes externas al presente artículo.

\section{Agradecimientos}

